\title{
Road Map for the Journal and Achieving New Horizon in Coming Years
}

\author{
Hitesh N. Modi ${ }^{1}$
}

Any published article is the proof of the clinician's academic growth and success of his career. Academic journal is usually considered the face of any representative body or organization. It also reflects the research activities carried out by its members and indirectly indicates how much its people are inclined to spreading and sharing their knowledge amongst others. Spine Association of Gujarat (SAG) is an esteemed organisation representing all the surgeons from Orthopaedic surgery and Neurosurgical specialty performing and involving in spine related treatment in their day-to-day practise. The purpose of bringing this journal is to make the face of our organisation shining like a star in the academic world. We want other parts of the world should know that our members are doing the best job in spine surgery, which is at par with the all advances in spine treatment. For this to achieve, we must stand and work together.

With the introduction of this scientific peer reviewed journal, we would like to invite articles from any part of the world and from any specialty, which is related to the spine care and related to the spine surgery. It is also a benchmark of SAG to exchange the knowledge in spine and spine related management amongst the members. It also facilitates knowledge and research exchange with the rest of the world. Let us think what SAG has achieved over the past years since its inception. SAG is currently involved in many scientific activities such as, regularly arranging one day conferences (one in three months), monthly medical forum to promote second line specialists, organising national conferences (by so far two ASSICON and one MISSICON) and also teaching newer surgeons (through individual capacity of the member) in form of fellowships. However, we still lack in publication and research activities. Our journal will provide a platform for its members to achieve

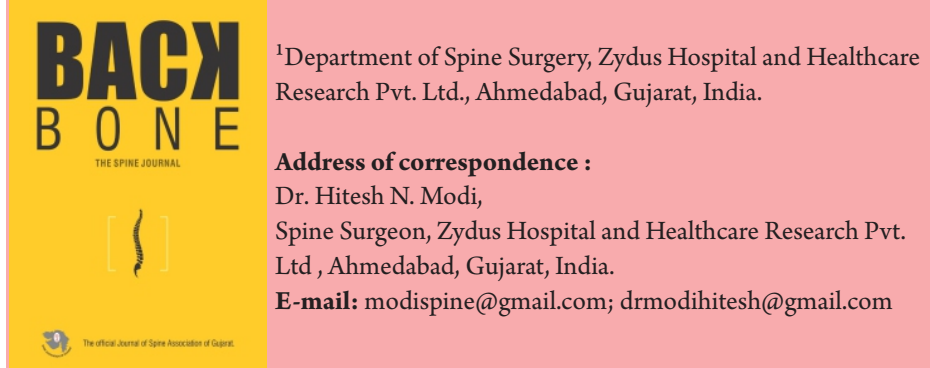

\section{their name scientifically recognised across the world.} The journal will be initially launched with online version that is readable easily on the internet. There are no processing fees for the article submission, review or publication and eve for the download. This will create a rapid acceptance of the journal in the scientific world. The expenditure is to be borne by the association. However, we also intend to print the journal in hard copy version in limited numbers, which will be distributed amongst our members and certain other organisations. Google scholar will also our primary search engine for the scientific search. The prestige of any journal is considered by how many abstracting and indexing services cover that journal. Citation index (indexing) is an ordered list of cited articles, each accompanied by a list of citing articles [1,2]. Currently SCI and SCI-expanded [3], which is published by ISI a part of Thomson Reuters, Scopus, which is a bibliographic database containing abstracts and citations for academic journal articles and ICI (Indian Citation Index), which is an online citation data for measuring performance of India research periodically are the major citation indexing services [4]. PubMed central is a free digital repository that archives publically accessible fulltext articles. More than 1600 peer reviewed scientific journals automatically deposit their articles in PubMed Central. As per my knowledge, MEDLINE, PubMed Central, ISI and Scopus are four major online bibliographic sites, and searched all over the world. Our primary aim of the journal is to list our article and journal in these online sites as soon as possible to make our research visible publically.

The citing article is identified as source and the cited article as reference. Our aim for the journal is to be an excellent source of research activities and to be known as reference book in the literature. The journal has its own website www.backbonejournal.com and one can electronically submit the manuscript as well as read archives from the site. The submission and decision time is aimed to decrease within period of three months, so that article becomes visible online at a faster pace. Currently we are going with two issues per year, and later we are planning to publish three or four issues per year to produce our academic activities more visible. Looking at the road map and future of the journal, our mission is to work for new opportunities for global exposure and improve

(C) 2020 | Back Bone: The Spine Journal (The Official Journal Of "Spine Association Of Gujarat") | Available on www.backbonejournal.com | doi:10.13107/bbj.2020.v01i01.001

This is an Open Access article distributed under the terms of the Creative Commons Attribution Non-Commercial License (http://creativecommons.org/licenses/by-nc/3.0) which permits unrestricted noncommercial use, distribution, and reproduction in any medium, provided the original work is properly cited. 
the impact factor of the journal once it is achieved. The transparency in the review process will continue from the beginning. We also aim at publishing specific and additional issues related to particular topic, which eventually represent and publish the academic work of a specialised person and provide research material like a book and ultimate for the particular topic. Publishing is teamwork. Therefore, we cordially invite you all to submit your manuscript to Backbone journal, which guarantees the highest level of peer review and quick publication after the acceptance. This is our journal and we must work and contribute together towards its growth.

\section{References}

1. Garfield, E., Citation indexing for studying science. Nature, 1970. 227(5259): p. 669-71.

2. Garfield, E., "Science Citation Index"--A New Dimension in Indexing. Science, 1964.144(3619):p.649-54
3. Fu, H.Z. and Y.S. Ho, Independent research of China in Science Citation Index Expanded during 1980-2011.JInformetr.7(1): p.210-222.

4. Marc, D.T., et al., Indexing Publicly Available Health Data with Medical Subject Headings (MeSH): An Evaluation of Term Coverage. Stud Health Technol Inform. 2015; 216: p. 529-33.
Conflict of Interest: NIL Source of Support: NIL

\section{How to Cite this Article}

Modi HN | Road Map for the Journal and Achieving New Horizon in Coming Years | Back Bone: The Spine Journal | October 2020-March 2021; 1(1): 1-2. 